\title{
Review
}

\section{Lectins as Bioactive Proteins in Foods and Feeds}

\author{
Koji Muramoto \\ Graduate School of Life Sciences, Tohoku University, Sendai 980-8577, Japan
}

Received January 26, 2017 ; Accepted March 16, 2017

Lectins, noncatalytic sugar-binding proteins of nonimmune origin, are widely distributed in the most common foods and feeds in varying amounts. Since many lectins, such as legume lectins, are relatively stable against heat denaturation and proteolytic digestion, the digestive tract is constantly exposed to biologically active lectins contained in fresh and processed foods. Lectins interact with the epithelial surface of the intestine and cause adverse effects, sometimes called food poisoning, in humans and animals. Meanwhile, many interesting biological functions have been discovered in lectins originating from foods or foodstuffs, including immunomodulating effects, selective cytotoxicity against cancer cells, antimicrobial and insecticidal activities, modulating effect on the intestinal transport system, and so on. This review aims to present the current state of research on lectins as bioactive proteins in foods and feeds in order to provide opportunities for application development.

Keywords: agglutinin, antinutritional factor, carbohydrate-binding protein, food lectin, lectin, phytohemagglutinin

\section{Introduction}

Lectins, noncatalytic carbohydrate-binding proteins of nonimmune origin, are widely distributed in almost all organisms, including vertebrates, invertebrates, bacteria and viruses (Sharon and Lis, 2003). Lectins are usually composed of globular subunit proteins, each of which contains one or more carbohydrate-binding sites. It should be emphasized that lectins show highly diverse carbohydrate specificity and physicochemical properties. They play important roles in diverse biological processes, such as cell-cell adhesion, cell communication, immune defense, signaling events, nutritional effects, cancer metastasis, microbial infection, and so forth, as counterparts of carbohydrates (Watanabe et al., 2013). The ubiquitous presence of lectins means that foods and foodstuffs contain varying amounts of lectins. In particular, foodstuffs of plant origin, such as seeds like cereals, legumes, fruits, or tubers, usually contain high levels of lectins. Typically, lectins account for $0.1-5 \%$ of the total legume seed protein (Van Damme et al., 1998). Since many lectins, such as legume lectins, are relatively stable against heat denaturation and proteolytic digestion, the digestive tract is constantly exposed to bioactive lectins contained in foods and feeds (Pusztai and Bardocz, 1996). Thus, lectins interact with the intestinal epithelial surface and cause

\footnotetext{
Abbreviations

ABA, white mushroom lectin; AOL, Aspergillus oryzae lectin; ASA, garlic lectin; CCK, cholecystokinin; CGA, Japanese jack bean lectin; ConA, concanavalin A; CSL3, chum salmon egg lectin; DB1, yam tuber lectin; FL, fluorescein; GNA, snowdrop lectin; HA, hemagglutination activity; HIV, human immunodeficiency virus; IL, interleukin; LY, lucifer yellow; MAL, banana lectin; MCT, monocarboxylic acid transporter-mediated pathway; MRPs, multidrug resistance associated protein-related efflux pathways; P-gp, P-glycoprotein-mediated efflux pathway; PHA, kidney bean lectin; PNA, peanut lectin; RBA, rice bran lectin; RH, rhodamine 123; SBA, soybean lectin; STA, potato lectin; TER, transepithelial electrical resistance; TJ, tight junction; UEA, Ulex europaeus lectin I; WGA, wheat germ lectin.
}

*To whom correspondence should be addressed. 
physiological effects in humans and animals, particularly when consumed in large quantities. Plant lectins, which are also called phytohemagglutinins, have been perceived as antinutritional factors together with enzyme inhibitors, mainly due to their adverse effects, i.e., non-pathogenic food-borne poisoning from the consumption of improperly or uncooked legumes (Van Damme et al., 1998; Kenmochi et al., 2015). In Japan, the "white kidney bean incident" occurred in 2006 following a TV broadcast introducing a new diet with powdered roasted white kidney beans (Phaseolus vulgaris). More than 1,000 viewers who tried the diet suffered from acute intestinal symptoms and 100 people were hospitalized. Lectins in the white kidney beans were suspected to be the causative agent (Ogawa and Date, 2014).

Meanwhile, recent extensive researches have revealed that lectins originating from foodstuffs or traditional herbal medicines express many interesting biological functions, including immunomodulating effects (Clement et al., 2010), selective cytotoxicity against cancer cells (Fu et al., 2011), antimicrobial and insecticidal activities (Dias et al., 2015), modulating effect on the intestinal transport system (Yamamoto et al., 2013), etc. In addition, many lectins are currently being used as important tools in the fields of biochemistry, cell biology and immunology, as well as for diagnostic and physiologic purposes in cancer research. Furthermore, their applicability as therapeutic agents has been demonstrated in clinical trials (Lam and $\mathrm{Ng}, 2011$ ).

It is known that the dietary intake of lectins in humans and animals can be significant. Hence, the physiological functions of lectins after consumption are receiving increasing attention. The aim of this review is to present the current state of research on lectins as bioactive proteins in foods and feeds in order to provide opportunities for application development.

\section{Lectins as antinutritional factors}

It is known that high doses of uncooked or partially cooked kidney beans can cause food poisoning (Banwell et al., 1993; Vasconcelos and Oliveira, 2004). The adverse effect of the lectin from red kidney beans (P. vulgaris), named PHA, is shown by a loss of epithelial resistance, leading to acute gastroenteritis. Moreover, PHA is fatal when ingested at high concentrations. Acute symptoms following ingestion include nausea, vomiting and diarrhea. Long-term intake in rodent models is characterized by increased cell turnover, gut hyperplasia and weight loss. Therefore, an effective processing approach must be implemented to inactivate PHA before consumption of PHA-containing legumes as food. Heating is the traditional processing technique to inactivate PHA; however, PHA is relatively resistant to thermal denaturation (Shi et al., 2007). Slow cooking without boiling does not eliminate lectin activity, even after heating for $5 \mathrm{~h}$ at $91^{\circ} \mathrm{C}$; whereas, activity in fully imbibed seeds could be completely abolished by heating at $100^{\circ} \mathrm{C}$ for $5 \mathrm{~min}$. Ultra high-pressure treatment (450 MPa) also effectively inactivated PHA (Lu et al., 2015).
What is the basis of plant lectin food poisoning? Locally, some lectins damage the luminal membranes of the epithelium, interfere with nutrient digestion and absorption, and stimulate shifts in the bacterial flora. Systemically, they disrupt nutrient metabolism, promote enlargement and/or atrophy of internal organs and tissues and alter hormonal and immunological function (Vasconcelos and Oliveira, 2004). Some plant lectins inhibited exocytosis and repair of the plasma membrane, and hence became toxic to gut epithelial cells wounded by mechanical and other stresses (Miyake et al., 2007). Such phenomena could be observed with concanavalin A (ConA) and wheat germ agglutinin (lectin) (WGA), which showed binding affinity to cells. Dye entry after laser-induced plasma membrane disruption was evaluated after incubation of cells with several plant lectins. Dye exclusion was inhibited by ConA and WGA, but not by Ulex europaeus agglutinin (lectin) I (UEA) and soybean agglutinin (lectin) (SBA), which showed no cell affinity. As this result indicates, each lectin has a specific carbohydratebinding activity. Since information encoded in cellular glycoproteins is usually translated into physiological effects via specific binding of lectins with their glycoconjugates, the interference of lectins with different carbohydrate specificities is thought to induce different biological reactions.

Food allergens share characteristic properties such as resistance to gut digestion. Although many lectins show such stability, they have less allergenicity than major allergens. Lectins are regarded as minor allergens in soybean and peanuts (Astwood et al., 1996).

Disturbances of hormonal homeostasis were observed in animals upon feeding lectins. PHA promoted pancreatic hypertrophy of rats in a dose-dependent manner. This was related to increasing plasma levels of a gut hormone, cholecystokinin (CCK), affecting gastrointestinal function and pancreatic growth (Vasconcelos and Olivera, 2004). In addition, some legume lectins have been shown to inhibit various intestinal and brush border enzymes such as sucrase, maltase, aminopeptidase and dipeptidyl peptidase.

The bacterial inhabitants of the human gastrointestinal tract constitute a complex ecosystem. The intestinal microflora may prevent infection by interfering with pathogens. The flora also includes low populations of potentially pathogenic organisms. The stability of the normal flora both discourages infection by exogenous pathogens and prevents overgrowth of potentially pathogenic members. Some legume lectins are known to induce bacterial overgrowth, possibly upsetting the balance of the normal flora and causing various symptoms of intestinal obstruction.

Although lectin activity, which is easily detected by agglutination against rabbit erythrocytes, can be found in a number of foods and foodstuffs (Tables 1 and 2). As already described, cereals, legumes and tubers usually contain high lectin levels. While most of these crops are cooked or processed before eating, many lectins can resist digestion, survive gut passage and bind to gastrointestinal cells and/or enter the circulation intact, thereby 
Table 1. Lectin activity of foodstuffs measured by hemagglutination assay.

\begin{tabular}{|c|c|c|c|c|c|c|c|c|c|c|c|}
\hline Common name & Scientific name & A & B & $\mathrm{C}$ & $\mathrm{D}$ & Common name & Scientific name & A & B & $\mathrm{C}$ & $\mathrm{D}$ \\
\hline Soybean & Glycine $\max$ & 23 & 3 & 7 & 8 & Banana & Musa paradisiac & 5 & ND & 3 & ND \\
\hline Garland chrysanthemum & Chrysanthemum coronarium & 14 & ND & 13 & 4 & Jew's ear & Auricularia auricula & 5 & 4 & ND & ND \\
\hline Yam tubers & Dioscorea batatas & 13 & 3 & 1 & $\mathrm{~N}$ & Peanut & Arachis hypogaea & 5 & 6 & 5 & 4 \\
\hline Kidney bean & Phaseolus vulgaris & 12 & 4 & 12 & 10 & Enokitake & Flammulina velutipes & 5 & ND & ND & ND \\
\hline Soy bean (Edamame) & Glycine Max & 11 & 1 & 11 & 3 & Walnut & Juglans mandshurica & 5 & 5 & 3 & 1 \\
\hline Taro & Colocasia esculenta & 11 & 5 & 8 & ND & Broad bean & Vicia faba & 4 & ND & 3 & 2 \\
\hline Japanese chestnut & Fagaceae Castanea & 10 & ND & ND & ND & Cherry & Prunus pseudocerasus & 4 & ND & ND & 2 \\
\hline Azuki bean & Vigna angularis & 9 & ND & 7 & 4 & Chinese chive & Allium tuberosum & 4 & ND & ND & 3 \\
\hline Snap pea & Pisum sativum & 8 & ND & 6 & ND & Coconut palm & Cocos nucifera & 4 & 3 & ]2 & ND \\
\hline Baker's garlic & Allium chinese & 8 & 4 & 5 & 2 & Kiwifluit & Actinidia chinensis & 4 & ND & ND & ND \\
\hline Cauliflower & Brassica oleracea & 7 & ND & 3 & 2 & Lime & Citrus aurantifolia & 4 & 3 & 3 & 3 \\
\hline White mushroom & Agaricus bisporus & 7 & ND & ND & ND & Sugar pea & Pisum sativum & 4 & ND & 4 & ND \\
\hline Galic & Allium sativum & 7 & 6 & 2 & 1 & Udo salad & Aralia cordata & 4 & ND & 5 & 4 \\
\hline Papaya & Carica papaya & 7 & ND & ND & ND & Chickweed & Stellaria neglecta & 4 & 4 & ND & ND \\
\hline Passion fruit & Passifora edulis & 7 & 2 & 3 & 3 & Bamboo shoot & Phyllostachys pubescens & 3 & ND & 4 & ND \\
\hline Potato & Solanum tuberosum & 7 & 5 & 6 & 4 & Garden bean & Phaseolus unlgaris & 3 & ND & 3 & ND \\
\hline Cowpea & Vigna unguiculata & 7 & 3 & 4 & 5 & Pumpkin & Cucurbita maxima & 3 & 3 & 5 & 3 \\
\hline Asparagus & Asparagus officinalis & 6 & ND & 5 & 3 & Spinach & Spinacia oleracea & 3 & ND & 3 & 2 \\
\hline Tomato & Lycopersicon esculentum & 6 & 5 & 5 & 5 & Lotusroots & Nelumbo mucifera & 3 & 2 & 2 & ND \\
\hline Summer squash & Cucurbita pepo & 6 & 1 & 6 & 4 & Bracken & Pteridium aquilinum & 3 & 4 & ND & 4 \\
\hline
\end{tabular}

Each food stuff $(1.0 \mathrm{~g})$ was homogenized with $2.0 \mathrm{~mL} 0.15 \mathrm{M} \mathrm{NaCl}$ and centrifuged. The supernatant was used for the hemagglutination assay. The assay was performed by the two-fold serial dilution method on 96 -well microtiter plates using a $4 \%$ rabbit erythrocyte suspension in $0.15 \mathrm{M} \mathrm{NaCl}$. The results were expressed as the titer values $\left(2^{-\mathrm{n}}\right)$ that had the maximum dilution for positive hemagglutination.

A: Normal sample. Hemagglutination activity (HA) expressed by the titer value. B: Heat-treated sample at $100^{\circ} \mathrm{C}$ for 24 min. C: Acid-treated sample. Sample solution $(700 \mu \mathrm{L})$ was mixed with $100 \mu \mathrm{L}$ of $1 \mathrm{M} \mathrm{HCL}$. After adjusting the pH to 7.0, HA was measured. D: Pepsin-treated sample. Sample solution $(700 \mu \mathrm{L})$ was mixed with $100 \mu \mathrm{L}$ of $1 \mathrm{M} \mathrm{HCL}$, and treated with $0.1 \mathrm{mg}$ of pepsin for $4 \mathrm{~h}$ at $37^{\circ} \mathrm{C}$. After adjusting the pH to 7.0, HA was measured. ND: HA was not detected.

Broccoli, carrot, celery, corn, edible burdock, egg plant, egoma, garden lettuce, garlic's bud, ginger, Japanese apricot, mango, melon, mioga, litchi, loquat, onion, pineapple, pulm, peach, persimmon, radish, salugreen, strawberry, sweet pepper, turnip, whelsh onion, western pear, and white radish sprouts: HA was not detected.

HA of some commercial foods were as follows; natto $(n=12)$, boiled black bean (8), soybean flour (7), steamed sweet potato (7), baked sweet potato (6), and French fries (4). Food samples were prepared as described above.

maintaining full biological activity (Gonzalez de Mejia and Prisecaru, 2005). For example, soybean contains $4.8 \pm 1.6 \mathrm{~g} / \mathrm{kg}$ of SBA, the activity of which is not altered by heating at $70^{\circ} \mathrm{C}$ for up to 90 min (Armour et al., 1998). It is noteworthy that fruits and vegetables containing lectins are frequently eaten without heating. Moreover, various kinds of lectins are distributed among fish and shellfish, which are also frequently consumed without heating (Ogawa et al., 2011). As is evident from historical eating habits, these lectins are harmless or labile against digestion and cooking.

\section{Beneficial effects}

While lectins are ubiquitous, toxic effects are rare. For instance, tomato (Lycopersicon esculentum) and mushroom (Agaricus bisporus) are often consumed raw or lightly cooked, and therefore large quantities of their lectins are consumed in an active form. These lectins are known to resist digestion in the gut of rats or humans (Kilpatrick et al., 1985); however, they are apparently safe when eaten raw (Rhodes, 1999). In practice, the dietary intake of lectins is low, and their activity has no measurable negative effect on nutritional performance. It is also true that low amounts of lectins may have some beneficial effects on biological systems, such as promoting gut regrowth after total parenteral nutrition, use as an oral vaccine adjuvant, and use in anticancer therapy (Pusztai and Boedocz, 1997; Vasconcelos and Oliveira, 2004).

Several recent studies have revealed various biological roles of lectins, which include innate immunity (Dambuza and Brown, 2015), endocytosis and intracellular transport of vector glycoprotein mechanisms (Yamamoto, 2009), blocking of HIV infection (Tanaka et al., 2009), and control of blood protein levels (Rydz et al., 2013). Therefore, it is not surprising that lectins manifest diverse activities, such as mitogenic, antitumor, immunomodulating, antifungal, antibacterial, antiviral, and insecticidal activities, which may find practical applications in the context of pharmaceutical safety considerations (Lam and $\mathrm{Ng}$, 2011).

\section{Effects on intestinal transport system}

Absorption of nutrients and food factors across the intestinal 
Table 2. Lectin activity of seafoods measured by hemagglutination assay.

\begin{tabular}{|c|c|c|c|c|c|c|c|c|c|c|c|c|c|}
\hline Common name & Scientific name & & A & $\mathrm{B}$ & $\mathrm{C}$ & $\mathrm{D}$ & Common name & Scientific name & & A & B & $\mathrm{C}$ & $\mathrm{D}$ \\
\hline \multirow[t]{4}{*}{ Sweetfish } & Plecoglossus altivelis & Muscle & ND & ND & ND & ND & Top shell & Turbo cornutus & Edible part & ND & ND & ND & ND \\
\hline & & Skin & ND & $\mathrm{ND}$ & ND & ND & Clam & Meretrix lusoria & Edible part & 7 & 5 & 7 & 6 \\
\hline & & Gill & 10 & 6 & 7 & 6 & Short-neck clam & Ruditapes philippinarum & Edible part & 6 & 5 & 6 & 4 \\
\hline & & Liver & ND & ND & ND & ND & Whelk & Neptunea arthritica & Edible part & 4 & 3 & 4 & 4 \\
\hline \multirow[t]{4}{*}{ Yellowtail } & Seriola quinqueradiata & a Muscle & ND & $\mathrm{ND}$ & ND & ND & Oyster & Crassostea gigas & Edible part & 4 & 2 & 5 & 5 \\
\hline & & Skin & ND & ND & ND & ND & Seasquirt & Halocythia roretzi & Edible part & 8 & ND & 8 & 4 \\
\hline & & Gill & 7 & 4 & 7 & 7 & Scallop & Patinopecten yessoensis & Edible part & ND & ND & ND & ND \\
\hline & & Liver & 7 & 3 & 7 & 8 & Octopus & Octopus berenice & Edible part & ND & ND & ND & ND \\
\hline \multirow[t]{4}{*}{ Sea bass } & Lateolabrax japonica & Muscle & ND & ND & ND & ND & Shrimp & Squilla oratoria & Edible part & 15 & 15 & 15 & 10 \\
\hline & & Skin & 6 & 6 & 4 & 4 & Squid & Ommastrephes sloani & Edible part & 4 & ND & 4 & ND \\
\hline & & Gill & 10 & 9 & 6 & 4 & Crab & Erimacrus isenbeckii & Edible part & ND & ND & ND & ND \\
\hline & & liver & 10 & 10 & 10 & 10 & & & Hepatopancreas & 10 & 10 & 10 & 10 \\
\hline \multirow[t]{4}{*}{ Pike eel } & Muraenesox cinereus & Muscle & ND & $\mathrm{ND}$ & ND & ND & Sea urchin & Strongylocentrotus nudus & Edible part & 10 & ND & 10 & 10 \\
\hline & & Skin & 6 & ND & 6 & ND & Sea cucumber & Sichopus japonicus & Edible part & 10 & ND & 10 & 10 \\
\hline & & Gill & 6 & 5 & 6 & 5 & Wakame & Undaria pinnatifida & Edible part & 10 & - & 10 & 10 \\
\hline & & Liver & 10 & 6 & 10 & 10 & Mozuku & Nemacystus decipiens & Edible part & 10 & - & 10 & 10 \\
\hline
\end{tabular}

Hemagglutination assay was performed as described in Table 1 except for the heat treatment. The results were expressed as the titer values $\left(2^{-\mathrm{n}}\right)$ that had the maximum dilution for positive hemagglutination. A: Normal sample. Hemagglutination activity (HA) expressed by the titer value. B: Heat-treated sample at $60^{\circ} \mathrm{C}$ for $60 \mathrm{~min}$. C: Acid-treated sample. Sample solution $(700 \mu \mathrm{L})$ was mixed with $100 \mu \mathrm{L}$ of $1 \mathrm{M}$ HCL. After adjusting the $\mathrm{pH}$ to 7.0 , HA was measured. D: Pepsin-treated sample. Sample solution $(700 \mu \mathrm{L})$ was mixed with $100 \mu \mathrm{L}$ of $1 \mathrm{M} \mathrm{HCL}$, and treated with $0.1 \mathrm{mg}$ of pepsin for $4 \mathrm{~h}$ at $37^{\circ} \mathrm{C}$. After adjusting the $\mathrm{pH}$ to 7.0, HA was measured. ND: HA was not detected. Muscle of jack mackerel, sea bream, and sardine showed no HA, but black rock fish and sea robin showed HA, $\mathrm{n}=10$ and 4, respectively. Commercial salted herring roe and ikura gave $\mathrm{HA}, \mathrm{n}=10$ and 2, respectively.

epithelium occurs by one or more different transport pathways, such as passive paracellular transport, passive transcellular transport, and carrier-mediated transport (Kosińska and Andlauer, 2013). The increased permeability of the intestinal epithelium has been linked to pathogenesis of inflammatory bowel disease, ulcerative colitis, Crohn's disease and food allergies. On the other hand, transient increase in intestinal transport could improve the bioavailability of desirable bioactive compounds that are normally poorly absorbed. Some dietary substances and drugs have been found to affect intestinal absorption (Konishi, 2005).

Food lectins were demonstrated to have modulating effects on the transport pathways across human intestinal Caco-2 cell monolayers, which have been used as in vitro models of the human small intestinal epithelium system (Table 3) (Yamamoto et al., 2013). Con A from jack bean, CGA from Japanese jack bean, PNA from peanut, RBA from rice bran, WGA from wheat germ, ASA from garlic, $\mathrm{ABA}$ from white mushroom, AOL from A. oryzae and CSL3 from chum salmon eggs decreased the transepithelial electrical resistance (TER) value, whereas DB1 from yam increased TER. The TER value reflects an effect on the tight junction (TJ)mediated paracellular pathway; a decrease in TER value indicates an increase in paracellular transport and vice versa. In fact, these lectins increased the transport of lucifer yellow (LY), a model compound of the paracellular pathway. SBA, RBA, WGA and CSL3 increased the transport of fluorescein (FL) in the monocarboxylic acid transporter-mediated pathway, but MAL from banana decreased FL transport. RBA, WGA, STA from potato,
AOL and CSL3 increased the transport of rhodamine $123(\mathrm{RH})$ for the p-glycoprotein-mediated efflux pathway, whereas ABA showed decreasing effects. These results indicate that lectins affect the transepithelial transport pathways in different manners, probably due to their specific binding affinities.

SBA, CGA and WGA increased isoflavone transport, but had no effect on aglycone transport through Caco-2 cell monolayers. SBA increased the transport of quercetin glycosides, whereas CGA and WGA had no effect (Ohno et al., 2006). The lectins increased the transport of calcium ions, but showed no effect on the transport of antioxidant dipeptides, carnosine and anserine. The TJ-mediated paracellular pathway is thought to provide a highly dynamic transport route for certain ions and hydrophilic molecules. The paracellular transport of compounds is regulated by the formation of a protein-protein network-epithelial junctional complex. Protein complexes connecting epithelial cells include TJs, gap junctions, adherens junctions (AJ) and desmosomes (Kosińska and Andlauer, 2013). Claudins are key structural and functional components of TJs. They are responsible for cation- and anion-selective pore formation and ion flux, measurable by TER. It has been proposed that the extracellular loops of claudins can create selective paracellular pores, which allow the passive diffusion of ions.

Among the lectins tested, CSL3 showed the most prominent effects toward various transport systems (Yamamoto et al., 2013). CSL3 is an L-rhamnose binding lectin contained in chum salmon (Oncorhynchus keta) eggs (Ikura), which is widely consumed as caviar in Japan and other countries. CSL3 is a homodimer of two 
Table 3. Effects of lectins on the transport system of human intestinal Caco-2 cell monolayers.

\begin{tabular}{|c|c|c|c|c|c|c|c|}
\hline & Lectin & Specificity & TJ & MCT & P-gp & $\begin{array}{c}\text { MRP2 } \\
\text { (apical) }\end{array}$ & $\begin{array}{c}\text { MRPs } \\
\text { (basolateral) }\end{array}$ \\
\hline SBA & ( soybean ) & GalNAc / Gal & - & $\uparrow$ & - & - & - \\
\hline Con A & ( Jackbean ) & Man / Glc & $\uparrow$ & - & - & $\downarrow$ & $\uparrow$ \\
\hline CGA & ( Jap. Jackbean ) & Man / Glc & $\uparrow$ & - & - & - & - \\
\hline PSA & ( garden pea ) & Man / Glc & - & - & - & - & $\uparrow$ \\
\hline PNA & ( peanut ) & Gal & $\uparrow$ & - & - & - & - \\
\hline RBA & ( rice ) & GlcNAc & $\uparrow$ & $\uparrow$ & $\uparrow$ & $\downarrow$ & - \\
\hline WGA & (wheat) & GlcNAc & $\uparrow$ & $\uparrow$ & $\uparrow$ & $\downarrow$ & - \\
\hline LEA & ( tomato ) & GlcNAc & - & - & - & - & - \\
\hline STA & ( potato ) & GlcNAc & - & - & $\uparrow$ & $\uparrow$ & $\downarrow$ \\
\hline ASA & ( garlic ) & Man & $\uparrow$ & - & - & $\uparrow$ & - \\
\hline DB1 & ( yam ) & Man & $\downarrow$ & - & - & - & - \\
\hline MAL & (banana) & Man / Glc & - & $\downarrow$ & - & $\uparrow$ & - \\
\hline DB3 & ( yam ) & Mal & - & - & - & - & $\downarrow$ \\
\hline ABA & ( mushroom ) & Gal & $\uparrow$ & - & $\downarrow$ & $\downarrow$ & - \\
\hline $\mathrm{AOL}$ & (A. oryzae ) & Fuc & $\uparrow$ & - & $\uparrow$ & $\downarrow$ & - \\
\hline CSL3 & ( salmon egg ) & Rha / Gal & $\uparrow$ & $\uparrow$ & $\uparrow$ & $\downarrow$ & $\uparrow$ \\
\hline
\end{tabular}

The effects were investigated by using fluorescent markers: Lucifer yellow for the paracellular pathway (TJ), fluorescein for the monocarboxylic acid transporter-mediated pathway (MCT), rhodamine 123 for P-glycoprotein-mediated efflux pathway (P-gp), and calcein (CA) for the multidrug resistance associated protein-related efflux pathways (MRPs). For CA transport experiment, the cell monolayers were pre-incubated with CA for $30 \mathrm{~min}$ and incubated with lectin solutions after washing the monolayers. The lection solutions were added only to the apical compartment. After incubating for $2 \mathrm{~h}$, CA contained in the apical and basolateral solutions, and the monolayers were quantitated by fluorescence analysis. Arrows indicate up-regulation and down-regulation, respectively. GalNAc, N-acetyl-D-galactosamine; Gal, D-galactose; Man, D-mannose; Glc, D-glucose; GlcNAc, N-acetyl-D-glucosamine; Rha, L-rhamnose; Fuc, L-fucose; Mal, maltose.

$20 \mathrm{kDa}$ subunits with an overall dumbbell-like shape (Shirai et al., 2009). To gain insight into the function of food lectins, the effect of CSL3 on TJ of Caco-2 cell monolayers was explored in more detail (Nemoto et al., 2014). CSL3 decreased the TER value significantly after 2-h incubation. This effect continued until 6-h incubation and was strengthened in a concentration-dependent manner. The addition of $10 \mathrm{mM}$ L-rhamnose quickly reversed the decrease in TER value by CSL3 to the control level, indicating that the effect was specific for sugar binding. CSL3 increased intracellular $\mathrm{Ca}^{2+}$ significantly after 2 -h incubation in a dosedependent manner, resulting in depolymerization of $\beta$-actin in the cytoskeleton, thereby causing reversible TJ structural and functional disruption without affecting the expression of $\mathrm{TJ}$ proteins such as claudin-1 (Nemoto et al., 2014).

The effects of food lectins on the transport system were confirmed using male Wister rats (unpublished data). Rats were fed $10-100 \mu \mathrm{g}$ of lectins once a day for a week, and were administered quercetin glycosides or isoflavone glycosides ( $100 \mathrm{mg} / \mathrm{kg}$ body weight) orally after fasting overnight. As a result, SBA increased the absorption of quercetin and isoflavones, whereas WGA did not show a significant effect. Histological observation showed that the lectins did not cause morphological changes in the small intestine at the doses tested.

\section{Insecticidal activity}

Plant lectins have been regarded as natural defense molecules against herbivorous animals due to their adverse effects on the gut system (Sharon and Lis, 1998). Similarly, plant lectins, which are resistant to digestive enzymes and bind to the insect gut, exhibit insecticidal activity against a large array of insect species (Ohizumi et al., 2009). The effects of lectins following ingestion by insect larvae include growth inhibition, reduced size and weight gain, interference in female fecundity, as well as reduced pupation and percentage of adult emergence, and increased total developmental time, which in some cases resulted in the death of the insect larvae. Such lectins are suggested to be promising agents against insect pests and have been engineered successfully into a variety of crops (Kato et al., 2010). This approach could be used as part of an integrated pest management strategy and caveat pest attack. GNA, a mannose-binding lectin from the bulb of snowdrop (Galanthus 
nivalis), has been extensively studied for application to transgenic plants, including wheat, rice, potatoes and tobacco.

A mannose-binding lectin (DB1) homologous in structure to GNA accounts for $20 \%$ of the total tuber protein in yam (Dioscorea batatas) (Ohizumi et al., 2009). DB1 inhibited the adult emergence of Helicoverpa armigera larvae by avidly binding to the larval brush border and peritrophic membrane. It is noteworthy that yam tubers can be stored for a year after harvesting, despite its high water content, and are generally consumed without cooking in Japan. DB1 has been applied to transgenic tobacco and rice to confer resistance to insect pests (Yoshimura et al., 2012).

\section{Antitumor activity}

Lectins are important tools in the fields of biochemistry, cell biology and immunology for differential glycan profiling (Lam and $\mathrm{Ng}$, 2011). In recent years, they have been utilized as sophisticated microarrays to evaluate glycan-related biomarkers on malignant tumors and various types of stem cells (Hirabayashi et al., 2013). Some of these lectins have been reported to possess antitumor activities via targeting programmed cell death, which is a cellintrinsic mechanism for eliminating harmful cells and maintaining homeostasis, including apoptosis and autophagy (Fu et al., 2011; Li et al., 2009). Epidemiological studies have shown that the incidence of colorectal cancer in countries where people consume an abundance of legumes is comparatively low (Hughes et al., 1997). The importance of various substances in legumes, such as isoflavones, protease inhibitors, saponins and phytates, are proposed for cancer prevention. Legume lectins have also been reported to possess significant antiproliferative and apoptosisinducing activities toward a variety of cancer cell types (Lam and $\mathrm{Ng}, 2010$ ). For example, a lectin isolated from Northeast China black beans induced mitochondrial dysfunction and apoptosis in colorectal cancer cells (Dan et al., 2016). The lectin bound to the tumor cell membrane as early as 30 min post-treatment and was gradually transported inside the cytoplasm within $3 \mathrm{~h}$, with some localizing in the Golgi apparatus and some in lysosomes. The transported lectin induced aggregation of the Golgi apparatus, resulting in endoplasmic reticulum stress and resultant cytotoxicity.

\section{Immunomodulating effects}

Nowell's discovery of the mitogenic activity of PHA on lymphocytes had a huge impact on various research fields, including immunology and cell biology, since lymphocytes had previously been regarded as terminal cells that could neither divide nor differentiate (Sharon and Lis, 1998). Since then, many mitogenic lectins have been isolated and characterized. These lectins are taken up into the gut barrier and subsequently transported throughout the body, resulting in antibody production and other immunological effects. PHA and several other common lectins induced human basophils to secrete interleukin-4 (IL-4) and IL-13, the key promoters of T helper type (Th2) cell responses and
IgE synthesis (Vasconcelos and Oliveira, 2004).

Garlic (Allium sativum), an important medicinal spice, displays a plethora of biological effects, including immunomodulation. Garlic lectins, ASA I and ASA II, are contained in the bulb as major proteins, and belong to the monocot mannose-specific lectins. Garlic lectins non-specifically activated mast cells and basophils in atopic subjects as a result of the higher density of IgE (Clement et al., 2010). More atopic subjects showed positive reaction in the skin prick test using garlic lectins than non-atopic (normal) subjects. These results suggest that ASAs are potent mitogens with potential utility in therapeutic immunomodulation, especially because they are derived from a safe dietary source. Lectins from other Allium sp. exert similar immunomodulating effects (Yamazaki et al., 2016).

\section{Antimicrobial activity}

Mannose-binding lectins exhibit significant activity against human immunodeficiency virus (HIV) and other viruses with an envelope (Akkouh et al., 2015). Viral envelope glycoproteins such as gp41 and gp120 cover the surfaces of retroviruses such as HIV and many other viruses. Since these envelope glycoproteins are heavily glycosylated with mannose residues, mannose-binding lectins interfere with viral attachment in the early stage of the replication cycle and suppress growth by interacting at the end of the virus infectious cycle. The mannose-binding lectins from cyanobacteria and algae display high anti-HIV potencies with nanomolar-picomolar $\mathrm{IC}_{50}$ values (Hirayama et al., 2016). Banana (Musa acuminata) lectin was observed to directly bind gp120 and block cellular entry of HIV, thereby suppressing HIV infection (Swanson et al., 2010).

Plant lectins have been regarded as natural defense molecules against animals and insects. They also play an important role in defense mechanisms against microbial attack (Dias et al., 2015). Some legume lectins have been shown to inhibit the growth of several phytopathogenic and non-pathogenic fungi (Ang et al., 2014). The lectins bind chitin of fungal cell walls, inhibiting growth and development. In antibacterial defense, lectins are correlated with pore-forming activity, which causes bacterial membrane permeabilization (Mukherjee et al., 2014). Agricultural losses are a challenging economic and food security problem. Global food security is threatened by population growth and the emergence and spread of crop pests, which is significantly increasing with climate change. Strategies to overcome the damage caused by pathogens include chemical treatment, conventional breeding and transgenic approaches. Transgenic plants expressing lectin genes have been shown to confer resistance against nematodes and insects (Dias et al., 2015).

\section{Perspectives}

Lectins contained in foods and feeds have long been perceived as antinutritional factors; nevertheless, it is suggested that the 
intake of lectins from diets and feeds can be significant. Several recent studies have reported that lectins show diverse effects, including antitumor, immunomodulating, antimicrobial, antiviral and insecticidal activities. This review aims to reexamine the health benefits of lectins when consumed appropriately. In recent years, extensive scientific evidence has emerged indicating that dietary patterns have specific health or disease outcomes. For instance, inhibiting the digestion and absorption of dietary lipids and carbohydrates is a recognized successful approach to weight management. In the continuing search for novel anti-obesity agents, numerous plant-derived phytochemicals have been screened for potential lipase, $\alpha$-amylase and $\alpha$-glucosidase inhibitory activities (El and Simsek, 2012). A significant negative relationship was observed between the glucose response to different starchy foods (expressed as the glycemic index) and the intake of some lectins in foods. The potential applicability of pulse lectins as a nutraceutical for controlling obesity is attributed to their ability to resist gastric digestion and their subsequent absorption into the bloodstream while remaining biologically active (Roy et al., 2010). In relation to human and animal health, there has currently been increased focus on bifidus factors that promote the growth of beneficial bacteria as well as growth inhibitors against harmful bacteria in the intestine. It is very possible that lectins function as bifidus factors, though there are few reports dealing with this research area. Hence, more attention should be focused on the physiological functions of lectins after consumption of foods and feeds.

Acknowledgement This work was supported by JSPS KAKENHI grant no. 26292111.

\section{References}

Akkouh, O., Ng, T. B., Singh, S. S., Yin, C., Dan, X., Chan, Y. S., Pan, W., Chi, R., and Cheung, F. (2015). Lectins with anti-HIV activity: a review. Molecules, 20, 648-668.

Ang, A. S. W., Cheung, R. C. F., Dan, X., Chan, Y. S., Pan, W., and Ng, T. B. (2014). Purification and characterization of a glucosamine-binding antifungal lectin from Phaseolus vulgaris cv. Chinese pinto beans with antiproliferative activity towards nasopharyngeal carcinoma cells. Appl. Biochem. Biotechnol., 172, 672-686.

Armour, J.C., Perera, R.L.C., Buchan, W.C., and Grant, G. (1998). Protease inhibitors and lectins in soya beans and effects of aqueous heattreatment. J. Sci. Food Agric., 78, 225-231.

Astwood, J. D., Leach, J. N., and Fuchs, R. L. (1996). Stability of food allergens to digestion in vitro. Nature Biotechnol., 14, 1269-1273.

Banwell, J. G., Howard, R., Kabir, I., Abriab, T. E., Diamond, R. H., and Abramowsky, C. (1993). Small intestinal growth caused by feeding red kidney bean phytohemaglutinin lectin to rats. Gastroenterology, 104, 1669-1677.

Clement, F., Pramod, S. N., Yeldur P., and Venkatesh, Y. P. (2010). Identity of the immunomodulatory proteins from garlic (Allium sativum) with the major garlic lectins or agglutinins. Int. Immunopharmacol., 10, 316-324.

Dambuza, I. M. and Brown, G. D. (2015) C-type lectins in immunity: recent developments. Curr. Opin. Immunol., 32, 21-27.

Dan, X., Ng, T. B., Wong, J. H., Chan,Y. S., Cheung, R. C. F., and Chan, W. Y. (2016). A hemagglutinin isolated from Northeast China black beans induced mitochondrial dysfunction and apoptosis in colorectal cancer cells. Biochim. Biophys. Acta, 1863, 2201-2211.

Dias, R. O., Machado, L. S., Migliolo, L., and Franco, O. L. (2015). Insights into animal and plant lectins with antimicrobial activities. Molecules, 20, 519-541.

El, S. N. and Simsek, S. (2012). Food technological applications for optimal nutrition: an overview of opportunities for the food industry. Comp. Rev. Food Sci. Food Safety, 11, 2-12.

Fu, L. L., Zhou, C. C., Yao, S., Yu, J. Y., Liu, B., and Bao, J. K. (2011). Plant lectins: Targeting programmed cell death pathways as antitumor agents. Int. J. Biochem. Cell Biol., 43, 1442-1449.

Gonzalez de Mejía, E. and Prisecaru, V.I. (2005). Lectins as bioactive plant proteins: A potential in cancer treatment. Crit. Rev. Food Sci. Nutr., 45, 425-445.

Hirabayashi, J., Yamada, M., Kuno, A., and Tateno, H. (2013). Lectin microarrays: concept, principle and applications. Chem. Soc. Rev., 42 , 4443-4458.

Hirayama, M., Shibata, H., Imamura, K., Sakaguchi, T., and Hori, K. (2016). High-mannose specific lectin and its recombinants from a carrageenophyta Kappaphycus alvarezii represent a potent anti-HIV activity through high-affinity gp120. Marine Biotechnol., 18, 144-160.

Hughes, J. S., Ganthavorn, C., and Wilson-Sanders, D. (1997). Dry beans inhibit azoxymethane-induced colon carcinogenesis in F344 rats. $J$. Nutr., 127, 2328-2333.

Kato, T., Hori, M., Ogawa, T., Muramoto, K., and Toriyama, K. (2010). Expression of gene for Dioscorea batatas tuber lectin 1 in transgenic tobacco confers resistance to green-peach aphid. Plant Biotechnol., 27, 141-145.

Kenmochi, E., Kabir, S. R., Ogawa, T., Naude, R., Tateno, H., Hirabayashi, J., and Muramoto, K. (2015). Isolation and biochemical characterization of Apios tuber lectin. Molecules, 20, 987-1002.

Kilpatrick, D. C., Pusztai, A., Grant, G., Graham, C., and Ewen, S. W. B. (1985). Tomato lectin resists digestion in the mammalian alimentary canal and binds to intestinal villi without deleterious effects. FEBS Lett., 185, 299-305

Konishi, Y. (2005). Transepithelial transport of microbial metabolites of quercetin in intestinal Caco-2 cell monolayers. J. Agric. Food Chem., 53, 601-607.

Kosińska, A. and Andlauer, W. (2013). Modulation of tight junction integrity by food components. Food Res. Int., 54, 951-960.

Lam, S. K. and Ng, T. B. (2010). First report of a haemagglutinin-induced apoptotic pathway in breast cancer cells. Biosci. Rep., 30, 307-317.

Lam, S. K. and Ng, T. B. (2011). Lectins: production and practical applications. Appl. Microbiol. Biotechnol., 89, 45-55.

Li, C. Y., Xu, H. L., Liu, B., Bao, and J. K. (2010). Concanavalin A, from 
an old protein to novel candidate anti-neoplastic drug. Curr. Mol. Pharmacol., 3, 123-128.

Lin, P., Ye, X., and Ng, T. B. (2008). Purification of melibiose-binding lectins from two cultivars of Chinese black soybeans. Acta. Biochim. Biophys., 40, 1029-1038.

Lu, Y., Liu, C., Zhao, M., Cui, C., and Ren, J. (2015). Structure and activity changes of phytohemagglutinin from red kidney bean (Phaseolus vulgaris) affected by ultrahigh-pressure treatments. J. Agric. Food Chem., 63, 9513-9519.

Miyake K, Tanaka T, and McNeil PL (2007). Lectin-Based Food Poisoning: A New Mechanism of Protein Toxicity. PLoS ONE, 2, e687.

Mukherjee, S., Zheng, H., Derebe, M. G., Callenberg, K. M., Partch, C. L., Rollins, D., Propheter, D. C., Rizo, J., Grabe, M., Jiang, Q.-X., and Hooper, L. V. (2014). Antibacterial membrane attack by a pore-forming intestinal C-type lectin. Nature, 505, 103-107.

Nemoto, R., Yamamoto, S., Ogawa, T., Naude, R., and Muramoto, K. (2015). Effect of chum salmon egg lectin on tight junctions in Caco-2 cell monolayers. Molecules, 20, 8094-8106.

Ogawa, H. and Date, K. (2014). The "white kidney bean incident" in Japan. Methods Mol. Biol., 1200, 39-45.

Ogawa, T., Watanabe, M., Naganuma, T., and Muramoto, K. (2011). Diversified carbohydrate-binding lectins from marine resources. $J$. Amino Acids, 2011, Article ID 838914, 20 pages.

Ohno, Y., Naganuma, T., Ogawa, T., and Muramoto, K. (2006). Effect of lectins on the transport of food factors in Caco-2 cell monolayers. $J$. Agric. Food Chem., 54, 548-553.

Pusztai, A. and Bardocz, S. (1996). Biological Effects of Plant Lectins on the Gastrointestinal Tract: Metabolic Consequences and applications. Trends Glycosci.Glycotechnol. 8, 149-165.

Rhodes, J. M. (1999). GM foods and the Pusztai affair. Br. Med. J., 318, 1284.

Roy, F., Boye, J. I., and Simpson, B. K. (2010). Bioactive proteins and peptides in pulse crops: pea, chickpea and lentil. Food Res. Int., 43, 432442.

Rydz, N., Swystun, L.L., Notley, C., Paterson, A.D., Riches, J.J., Sponagle, K., Boonyawat, B., Montgomery, R.R., James, P.D., and Lillicrap, D. (2013). The C-type lectin receptor clec4m binds, internalizes, and clears von Willebrand factor and contributes to the variation in plasma von Willebrand factor levels. Blood, 121, 5228-5237.

Sharon, N. and Lis, H. (2003). "Lectins." Kluwer Academic Publishers,
Dordrecht, Nethewrlands.

Shi, J., Xue, S. J., Kakuda, Y., Ilic, S., and Kim, D. (2007). Isolation and characterization of lectins from kidney beans (Phaseolus vulgaris). Process Biochem., 42, 1436-1442.

Shirai, T., Watanabe, Y., Lee, M., Ogawa, T., and Muramoto, K. (2009). Structure of rhamnose-binding lectin CSL3: Unique pseudo-tetramic architecture of pattern recognition protein. J. Mol. Biol., 391, 390-403.

Swanson, M. D., Winter, H. C., Goldstein, I. J., and Markovitz, D. M. (2010). A lectin isolated from bananas is a potent inhibitor of HIV replication. J. Biol. Chem., 285, 8646-8655.

Tanaka, H., Chiba, H., Inokoshi, J., Kuno, A., Sugai, T., Takahashi, A., Ito, Y., Tsunoda, M., Suzuki, K., and Takenaka, A. (2009). Mechanism by which the lectin actinohivin blocks HIV infection of target cells. Proc. Natl. Acad. Sci. USA, 106, 15633-15638.

Van Damme, E. J. M., Peumans W. J., Pusztai, A., and Bardoez, S. (1998). Plant lectins in mammalian nutrition, immunology, metabolism and as oral therapeutic and immune agents. In "Handbook of plant lectins: Properties and Biochemical Applications.” ed. by Van Damme, E. J. M., Peumans W. J., Pusztai, A., Bardoez, S., John Wiley \& Sons, Chichester, England, pp. 31-55.

Vasconcelos, I. M. and Oliveira, J. T. A. (2004). Antinutritional properties of plant lectins. Toxicon, 44, 385-403.

Watanabe, Y., Naganuma, T., Ogawa, T., and Muramoto, K. (2013). Lectins of marine origin and their clinical applications. pp. 33-54. 'Antitumor potential and other emerging medicinal properties of natural compounds' Ed. By E.F. Fang and T.B. Ng, Springer.

Yamamoto, K. (2009). Intracellular lectins involved in folding and transport in the endoplasmic reticulum. Biol. Pharm. Bull., 32, 767-773.

Yamamoto, S., Tomiyama, M., Nemoto, R., Naganuma, T., Ogawa, T., and Muramoto, K. (2013). Effects of food lectins on the transport sysytem on human intestinal Caco-2 cell monolayers. Biosci. Biotechnol. Biochem., 77, 1917-1924.

Yamazaki, T., Ogawa, T., Muramoto, K., Nakahigashi, J., Takeuchi, A., and Ueda, H. (2016). Isolation and biochemical characterization of mucus proteins of Japanese bunching onion (Allium fistulosum) green leaves. Food Sci. Technol. Res., 22, 235-243.

Yoshimura, S. Komatsu, M., Kaku, K., Hori, M., Ogawa, T., Muramoto, K., Kazama, T., Ito, Y., and Toriyama, K. (2012). Production of transgenic rice plants expressing Dioscorea batatas tuber lectin 1 to confer resistance against brown plant hopper. Plant Biotechnol., 29, 501-504. 